\title{
Effectiveness of Criminal Justice Liaison and Diversion Services for Offenders With Mental Disorders: A Review
}

\author{
David A. Scott, Ph.D. \\ Sinead McGilloway, Ph.D. \\ Martin Dempster, Ph.D. \\ Fred Browne, B.Sc., F.R.C.Psych. \\ Michael Donnelly, Ph.D.
}

\begin{abstract}
Objective: The authors reviewed studies of the effectiveness of criminal justice liaison and diversion (CJLD) services in which outcomes of participants in these services were compared with those of offenders with mental illness who received no intervention or a standard intervention. The authors synthesized existing evidence with respect to changes in mental health status or criminal recidivism. Methods: A comprehensive search (1980-2012) of more than 30 generic and specialist databases identified 6,571 published and unpublished studies. The studies, which varied considerably in methodological approach and overall quality, were systematically appraised according to Campbell-Cochrane guidelines. Ten studies met inclusion criteria. Key outcomes included a reduction in offending and postintervention changes in mental health. Results: Synthesized findings indicated that CJLD services appeared to be effective in identifying offenders with mental disorders and that participation in CJLD services had a positive impact on criminal justice and mental health outcomes. Conclusions: Although the methodologies of existing studies are only moderately rigorous, the overall findings suggest that CJLD services can be beneficial. Their effectiveness depends on the model of service delivery, the availability of community services, and the engagement of offenders with mental disorders in treatment. The successful implementation of CJLD services requires a clearer recognition of the importance of systems-of-care principles. (Psychiatric Services 64:843-849, 2013; doi: 10.1176/appi.ps.201200144)
\end{abstract}

$\mathrm{T}$ here is growing concern regarding the prevalence, nature, and treatment of offenders with mental disorders (1-7), and jurisdictions have responded to this challenge in various ways. Two distinct service models have developed in the United Kingdom, including liaison services based in police stations and court-based diversion services. The dominant service model employed in the United States is the mental health court (MHC) (8). Despite the widespread implementation of these services, little is known about their overall effectiveness.

Dr. Scott is with the Centre for Public Health, Dr. Dempster is with the School of Psychology, and Dr. Donnelly is with the Centre for Excellence in Public Health, all at the Queen's University, Belfast, United Kingdom. Dr. McGilloway is with the Department of Psychology, National University Ireland, Dublin, Ireland. Dr. Browne is with Medical Associates, Belfast, United Kingdom. Send correspondence to Dr. Scott at ICS-B, Grosvenor Rd., Belfast BT12 6BJ, United Kingdom (e-mail: david.scott@qub.ac.uk).

The aim of this review was to identify, evaluate, and synthesize the best available evidence on the effectiveness of criminal justice liaison and diversion (CJLD) services. Liaison services seek to identify offenders with a mental illness and link them to appropriate mental health services in the community. Most employ community psychiatric nurses to complete assessments and provide general guidance to criminal justice system staff. Clients are unlikely to require imprisonment or hospitalization (9). Diversion services vary considerably and may range from a single visit to the court by a community psychiatric nurse to the involvement of full multidisciplinary teams (9). Most diversion services in the United Kingdom are based in magistrates' courts, which act as a filter through which most cases must pass (10-12). Clients who are appropriately referred are likely to require treatment or hospitalization. MHCs follow a model of therapeutic jurisprudence. Key components include a separate court docket for offenders with mental disorders, a judge trained in mental health issues, and a "treatment team" of mental health and legal professionals. MHCs aim to divert offenders with mental disorders to appropriate services, encourage treatment compliance, and reduce recidivism $(4,13,14)$.

This study aimed to evaluate and synthesize the best available evidence on the effectiveness of CJLD 
service models with respect to changes in mental health status or criminal recidivism.

\section{Methods}

\section{Literature search}

A scoping search showed that CJLD services are not clearly defined. Consequently, a broad strategy that involved 93 distinct criminal justice and mental health keywords (for example, jail diversion, diversion program, liaison service, liaison program, crime, criminal behavior, and mental health) was employed to ensure as comprehensive a search as possible. More than 30 generic and specialist databases were searched, including MEDLINE, EMBASE, Science Citation Index, PsycINFO, C2-SPECTR, Applied Social Sciences Index, and Psi-Tri. Keyword searches were completed by using Internet search engines, and key journals and the reference lists of all retrieved papers were hand searched. The search process was completed by May 2012 (full details of the search strategy are available from the first author)

\section{Inclusion criteria}

Eligible studies were experimental or quasi-experimental and included one or more intervention groups and at least one comparator group. The comparator groups received either no intervention or a standard intervention. Studies with single-group designs were not eligible for inclusion. Studies were included if participants were assigned randomly to an intervention group or comparator group or matched individually on key variables or if data indicating initial group equivalence were reported. Studies were not included if it was clear that the comparator group contained individuals who did not meet the criteria for inclusion in the intervention group. Only studies that were based on outcome measures, such as recidivism rates, or changes in mental health status, as evidenced by one or more standardized measures (that is, valid measures that were administered in a uniform way) were included. Finally, studies were included for consideration if they were published between 1980 and 2012 and focused on adults who had not yet received a custodial sentence. Studies of prison in-reach services and services provided within prisons or in other locations were excluded (full details of the inclusion and exclusion criteria are available from the first author).

\section{Data extraction and quality assessment}

The search process identified 6,571 citations. Titles were examined to identify papers that were related to CJLD services only; studies with clearly irrelevant titles were removed at this stage, leaving 462 papers. The abstracts of all 462 papers were reviewed by using a screening form (15), after which 96 papers remained. The form provided the basis for a systematic assessment of each abstract according to prespecified inclusion and exclusion criteria. Only abstracts and papers that clearly did not meet these criteria were excluded. Abstract screening was completed by one reviewer (DAS), and a randomly selected sample of $10 \%$ of the articles $(\mathrm{N}=46)$ was also screened by a second reviewer; $100 \%$ agreement was achieved.

A total of 20 articles met the inclusion criteria, and each was subjected to a critical appraisal by using a checklist based on published guidelines (15-17). Full-text data extraction was completed by one reviewer (DAS). Data extraction forms were then shared with a second reviewer (MD) who made an independent assessment on the basis of this summary information; again $100 \%$ agreement was achieved. This systematic appraisal of selected papers identified biases related to study design and implementation, and only ten studies were subsequently deemed eligible for data extraction and synthesis. A narrative synthesis (rather than a meta-analysis) was undertaken because of the diverse nature of the services, study designs, and outcome measures employed (17). The results are organized and presented according to the three main types of CJLD services that emerged from the systematic search and appraisal.

\section{Results}

\section{MHCs with ACT}

An evaluation of an MHC that employed assertive community treatment
(ACT) to implement and monitor court-prescribed community services in Santa Barbara County, California, was the only randomized controlled study identified $(18,19)$ (Table 1). Participants had a serious mental illness and had been charged with a felony or misdemeanor and had at least one previous charge. A judge and the MHC treatment team met each study participant after his or her admission to court and agreed on a treatment plan. Participants returned to court either weekly or biweekly to discuss their progress, and the court could impose sanctions (including days in jail) for noncompliance with treatment.

A notable feature of this court was the use of ACT to implement and monitor court-prescribed community services. A further feature-and one not found in other reviewed studieswas the use of dedicated services designed specifically for MHC participants. MHC participants had exclusive access to services, including vocational rehabilitation, priorityaccess housing, and programs designed to assist with substance abuse management, independent living, and symptom improvement. Comparator clients experienced traditional criminal court proceedings, although they also had access to well-configured services, similar to those used by MHC participants, through the county's long-term care team.

In terms of criminal justice system outcomes, both groups experienced a significant reduction in jail days. This finding was statistically significant when participants who had been imprisoned or who were the most frequent offenders during the study follow-up period were excluded from the analysis. The single most important factor associated with imprisonment during the study period was the severity of drug abuse on study entry. In terms of psychosocial outcomes, MHC participation was associated with statistically significant improvements in substance abuse and quality of life and reduced symptomatology. However, comparator clients also experienced similar improvements in global functioning and alcohol use. 
Table 1

Studies of mental health courts (MHCs) with and without assertive community treatment (ACT)

\begin{tabular}{|c|c|c|c|}
\hline Study & Outcome measures & Summary of results & Main threats to validity \\
\hline \multicolumn{4}{|l|}{ With ACT } \\
\hline $\begin{array}{l}\text { Cosden et al., } \\
2003 \text { (18) }\end{array}$ & $\begin{array}{l}\text { 32-item Behavioral and } \\
\text { Symptom Identification } \\
\text { Scale (BASIS-32); } \\
\text { Lehman Quality of Life } \\
\text { Interview, short form; } \\
\text { Addiction Severity } \\
\text { Index (ASI); Global } \\
\text { Assessment of } \\
\text { Functioning (GAF); } \\
\text { recidivism }\end{array}$ & $\begin{array}{l}\text { Follow-up at } 12 \text { months; } \\
\text { improvements on psychological } \\
\text { distress scores for both groups; } \\
\text { MHC group more independent } \\
\text { at follow-up, with greater } \\
\text { improvement in alcohol abuse }\end{array}$ & $\begin{array}{l}\text { Authors removed the most } \\
\text { frequent and most serious } \\
\text { offenders from the analysis; } \\
\text { the intervention provided } \\
\text { to the intervention and } \\
\text { comparator groups was } \\
\text { similar; lack of blinding } \\
\text { regarding study condition } \\
\text { for both judges and case } \\
\text { managers may have } \\
\text { affected the treatment } \\
\text { provided. }\end{array}$ \\
\hline $\begin{array}{l}\text { Cosden et al., } \\
2005 \text { (19) }\end{array}$ & $\begin{array}{l}\text { BASIS-32; Lehman Quality } \\
\text { of Life Interview, short } \\
\text { form; ASI; GAF }\end{array}$ & $\begin{array}{l}\text { Follow-up at } 24 \text { months; BASIS-32 } \\
\text { scores, life satisfaction, and drug } \\
\text { scores improved for both groups, } \\
\text { with greater improvements for } \\
\text { MHC participants; GAF scores } \\
\text { improved for both groups; both } \\
\text { groups used similar amounts of } \\
\text { service hours; MHC participants } \\
\text { used more services earlier in the } \\
\text { follow-up period. }\end{array}$ & Same as above \\
\hline \multicolumn{4}{|l|}{ Without ACT } \\
\hline $\begin{array}{l}\text { Boothroyd et al., } \\
2003(20)\end{array}$ & $\begin{array}{l}\text { Self-reported service } \\
\text { use; insurance } \\
\text { records of service use }\end{array}$ & $\begin{array}{l}\text { More MHC users received } \\
\text { services, but the difference was } \\
\text { not statistically significant. }\end{array}$ & $\begin{array}{l}\text { Participants were matched } \\
\text { according to age, sex, } \\
\text { race-ethnicity, and Brief } \\
\text { Psychiatric Rating Scale } \\
\text { (BPRS) scores only; violent } \\
\text { offenders were not accepted } \\
\text { by the MHC; lack of statistical } \\
\text { power }\end{array}$ \\
\hline $\begin{array}{l}\text { Boothroyd et al., } \\
2005(21)\end{array}$ & $\begin{array}{l}\text { BPRS; self-reported } \\
\text { service use; insurance } \\
\text { records of service use }\end{array}$ & $\begin{array}{l}\text { BPRS scores did not improve for } \\
\text { either group regardless of } \\
\text { treatment receipt }\end{array}$ & Same as above \\
\hline $\begin{array}{l}\text { Christy et al., } \\
2005(22)\end{array}$ & $\begin{array}{l}\text { Time in jail for index } \\
\text { offense; arrest data } 1 \\
\text { year after the court } \\
\text { appearance; } \\
\text { self-reported violent } \\
\text { behavior }\end{array}$ & $\begin{array}{l}\text { MHC participants experienced } \\
\text { fewer days in jail during follow-up; } \\
\text { both groups had fewer arrests than } \\
\text { before study entry and similar } \\
\text { time to rearrest; no significant } \\
\text { differences were noted in } \\
\text { self-reported aggressive acts. }\end{array}$ & Same as above \\
\hline $\begin{array}{l}\text { McNiel and Binder, } \\
2007 \text { (24) }\end{array}$ & $\begin{array}{l}\text { Recidivism in the year } \\
\text { after arrest }\end{array}$ & $\begin{array}{l}\text { At } 12 \text { months, MHC participation } \\
\text { predicted a longer time to any } \\
\text { new charge; at } 18 \text { months, } \\
\text { MHC "graduates" had a longer } \\
\text { time to any new charge. }\end{array}$ & $\begin{array}{l}\text { Groups differed at baseline } \\
\text { in severity of mental disorder, } \\
\text { racial-ethnic background, } \\
\text { homelessness status, and } \\
\text { offense history; MHC } \\
\text { participants were volunteers }\end{array}$ \\
\hline $\begin{array}{l}\text { Moore and Hiday, } \\
2006(25)\end{array}$ & $\begin{array}{l}\text { Recidivism; severity } \\
\text { of recidivism }\end{array}$ & $\begin{array}{l}\text { MHC participants were rearrested less } \\
\text { often and for less serious crimes; } \\
\text { their rate of rearrest was slower. }\end{array}$ & $\begin{array}{l}\text { Groups differed at baseline } \\
\text { on measures of age, } \\
\text { race-ethnicity, prior offense } \\
\text { severity, and previous days } \\
\text { in jail; possible selection } \\
\text { bias because judges selected } \\
\text { comparator participants; } \\
\text { high dropout rate }\end{array}$ \\
\hline $\begin{array}{l}\text { Steadman et al., } \\
2011(23)\end{array}$ & $\begin{array}{l}\text { Recidivism; number } \\
\text { of jail days }\end{array}$ & $\begin{array}{l}\text { Fewer rearrests for MHC participants; } \\
\text { MHC "graduates" had fewer } \\
\text { rearrests than MHC participants } \\
\text { whose involvement was terminated; } \\
\text { MHC participants spent significantly } \\
\text { fewer days incarcerated in } 18 \text { months } \\
\text { after index arrest. }\end{array}$ & $\begin{array}{l}\text { MHCs were large, and findings } \\
\text { may not be transferable to } \\
\text { other settings; findings were } \\
\text { not replicated for all MHCs; } \\
\text { when calculating days in } \\
\text { the community, authors } \\
\text { were unable to include days } \\
\text { absent for noncriminal } \\
\text { reasons, such as inpatient stays. }\end{array}$ \\
\hline
\end{tabular}




\section{MHCs without ACT}

The review identified four studies related to MHCs without ACT (Table 1). These included a single evaluation of the Broward County, Florida, MHC (20-22), a multisite study examining the effectiveness of four large, wellestablished MHCs (23), plus two further studies $(24,25)$. All four evaluations employed a quasi-experimental design, although there were some differences in their execution. Two studies employed a matched design in which the MHC group and comparator group were matched on sociodemographic, criminal, and diagnostic variables $(20,24)$, and the second study also matched groups on symptomatology $(21,22)$. The other two studies employed a nonequivalent comparison group design whereby participants were matched on variables with statistical control for other between-group differences $(23,25)$. Further methodological differences existed in terms of comparator groups, each of which included either jail detainees (24), court attendees from a neighboring county (20-22), participants who had attended court during the previous year (25), or participants who were eligible for the MHC but who were not referred to the service (23). Although all the evaluations examined MHCs, the MHCs varied considerably in terms of size, staffing, procedures, and eligibility criteria.

Significantly more MHC participants than comparator clients received services during the follow-up period (20-23). Comparator clients were charged with new or violent crimes significantly earlier in the follow-up period (24). MHC participants were much less likely than comparator clients to receive new criminal charges and significantly less likely to be rearrested (25), even when time living in the community was taken into consideration (23). In two studies, comparator clients and those who entered the MHC and subsequently dropped out or had their treatment terminated were more likely to experience future arrests $(23,25)$. Only one study noted an overall increase in psychiatric symptoms during follow-up, albeit among both groups (21).

\section{Diversion services}

Two studies examined diversion services, both of which employed a nonequivalent control group design (Table 2). One reported outcomes from a national multisite study examining the effectiveness of eight diversion services across the United States (26). The second study examined a court-based diversion service in which the comparator group comprised eligible detainees who attended court when the diversion service was unavailable (27).

The multisite study pooled findings from eight local site evaluations and highlighted major differences in the models of diversion employed in terms of eligibility criteria, the number of service personnel and their professional backgrounds, the location of the court within the criminal justice system, and the treatments provided (26). Few consistent findings for all service models were recorded. When data from the eight study sites were examined collectively, diversion was associated with increased service use; overall, however, neither diverted nor comparator clients had high levels of service use. When data from all study sites were combined, an improvement in mental health status was found, although this finding was noted in a minority of individual sites. With regard to criminal justice system outcomes, diversion was not associated with any significant reduction in recidivism. An analysis of results related to quality of life found considerable variation across the study sites, thereby precluding any definitive conclusions.

Overall, results from the multisite study illustrated that diverted clients were more likely to be female, psychotic, and previously hospitalized and to have a criminal history that included a violent offense (26). Nondiverted participants were more likely to have extensive drug and alcohol treatment histories, a diagnosis of major mood disorder, more previous arrests, and better employment histories. The authors found that overall, individuals could be diverted from the justice system into community care with no increased risk of rearrest. However, several individual sites did not record significant improvements in measures of criminal recidivism, mental health, or substance abuse.

The second diversion study also found that a greater proportion of the diverted clients had a dual diagnosis and had committed more serious offenses (27). Diverted clients charged with more serious crimes also experienced significantly fewer days' imprisonment than comparator clients with similar charges. The authors found that this service model may be an effective way to reduce time in jail for people with serious mental illness, although only detainees charged with more serious crimes appeared to benefit in terms of spending more time in the community.

\section{Diversion into \\ compulsory hospital care}

One study examined a diversion service designed to identify offenders with mental disorders and divert them to a hospital, where they were involuntarily admitted (9) (Table 2). This service was available in two London magistrates' courts and was designed to facilitate the identification and assessment of people with mental illness who appear at court and, when necessary, ensure their rapid referral to services. Detainees suspected of having a mental illness were interviewed by a psychiatrist, social worker, and nurse. A report was then provided to all parties relevant to the case, and, when appropriate, detainees were compulsorily admitted to psychiatric inpatient care.

This evaluation used a quasiexperimental matched-pairs design. Court participants were matched to another patient who had been compulsorily admitted from the community to the same hospital. Patients who were admitted through the court diversion scheme were compared with those admitted by community referral on a range of routinely recorded indicators. On admission, both groups were similar in terms of variables such as gender, racial-ethnic status, and the likelihood of having experienced a psychiatric admission during the previous year. However, those admitted through the court were younger and were more likely to be abusing alcohol or drugs.

Both groups had a similar pattern of diagnoses and behavior when in 
Table 2

Studies of diversion services

\begin{tabular}{|c|c|c|c|}
\hline Study & Outcome measures & Summary of results & Main threats to validity \\
\hline $\begin{array}{l}\text { Broner et al., } \\
2004 \text { (26) }\end{array}$ & $\begin{array}{l}\text { Colorado Symptom Index; 12-item } \\
\text { Short Form Health Survey; } \\
\text { Michigan Alcohol Screening Test; } \\
\text { Drug Abuse Screening Test; } \\
\text { Dartmouth drug and alcohol } \\
\text { calendar; Lehman Quality of Life } \\
\text { Interview; recidivism }\end{array}$ & $\begin{array}{l}\text { Diversion was associated with } \\
\text { increased drug use, reduced } \\
\text { psychiatric symptoms, and } \\
\text { increased service use; it was not } \\
\text { associated with reduced recidivism. }\end{array}$ & $\begin{array}{l}\text { Measures of service use varied } \\
\text { across study sites; groups and } \\
\text { models of service provision } \\
\text { varied across sites. }\end{array}$ \\
\hline $\begin{array}{l}\text { Hoff et al., } \\
\qquad 1999(27)\end{array}$ & $\begin{array}{l}\text { Days in jail and days in hospital in } \\
\text { year after arrest }\end{array}$ & $\begin{array}{l}\text { Diversion was associated with fewer } \\
\text { days in jail for participants with } \\
\text { serious mental illnesses only; } \\
\text { female participants spent a longer } \\
\text { time than males in jail or in the } \\
\text { hospital. }\end{array}$ & $\begin{array}{l}\text { Significant differences between } \\
\text { groups at baseline }\end{array}$ \\
\hline $\begin{array}{l}\text { James et al., } \\
2002(9)\end{array}$ & $\begin{array}{l}\text { Change in mental state; engagement } \\
\text { with follow-up services; } \\
\text { subsequent readmission and } \\
\text { reconviction }\end{array}$ & $\begin{array}{l}\text { Persons admitted through the court } \\
\text { and those admitted through } \\
\text { community referral had similar } \\
\text { outcomes on most variables; } \\
\text { substance abuse was associated } \\
\text { with future offending and hospital } \\
\text { admissions. }\end{array}$ & $\begin{array}{l}\text { Many differences between } \\
\text { groups at baseline; small } \\
\text { samples; researchers not } \\
\text { blinded to study condition }\end{array}$ \\
\hline
\end{tabular}

the hospital. Individuals admitted through court and those admitted by community referral had hospital stays of similar duration, and the length of time to readmission during the twoyear follow-up period was also similar. For both groups, the most significant predictors of readmission were a diagnosis of psychosis, an inpatient psychiatric admission in the previous two years, and use of illicit drugs, rather than further criminal behavior.

\section{Discussion}

The findings from this review suggest that CJLD services provide an opportunity to identify offenders with mental disorders and to connect them to appropriate services. A key principle underpinning diversion is that when criminal behavior suggests the presence of mental illness, offenders should receive treatment rather than punishment. In addition, the principle of equivalence posits that standards for services for offenders with mental disorders, such as CJLD services, should be equivalent to standards for services provided in the community to patients with a mental disorder who do not come into contact with the criminal justice system $(28,29)$.

However, provision of services that are capable of meeting the mental health needs of offenders within the justice system (1-3) is a difficult task
(30). Offenders with mental disorders could receive preferential access to already scarce community services, or current funding could be diverted from community programs to provide specialized services for this client group. However, no evidence suggests that this pattern of service utilization currently exists. Our review examined all reported CJLD evaluations that used an experimental or quasi-experimental design and that were based on a standardized outcome indicator, such as recidivism, or a change in mental health status. Although a relatively small number of studies met these criteria, the observed pattern of results provides cautious support for the CJLD model. However, the strength of the available evidence is insufficient to fully endorse the diversion of offenders with mental disorders from the criminal justice system into the care of health and social services. This uncertainty is attributable to a number of factors, including the generally weak nature of the research designs, variation in CJLD models, and the availability, quality, and appropriateness of community services available to CJLD participants.

\section{Quality of studies reviewed}

Only one of the ten reviewed studies involved the random allocation of participants to study groups $(18,19)$. This study examined a well-configured and well-resourced MHC that utilized an ACT model to ensure that participants complied with treatment recommendations. As noted above, both MHC participants and comparator clients showed improvements in levels of recidivism and in psychosocial functioning. However, these improvements were observed only among offenders who were not imprisoned or who were least likely to reoffend during the study period. The removal from the analysis of offenders with these characteristics suggests that the MHC option may not be equally effective for all offenders with mental disorders. Few overall differences were found between the two study groups, and this may be partly due to the observed similarities between the interventions provided to MHC participants and comparator clients. In addition, some anecdotal evidence suggests that the lack of blinding to study condition may have affected the behavior of participants, case managers, and court officials. In short, it is possible that the comparator option in this study was contaminated to some extent and was not, therefore, an accurate reflection of routinely provided services.

The remaining studies employed quasi-experimental methods. They 
attempted to show initial group equivalence on a number of key variables or to statistically control for observed differences. However, because of the complexity of the various CJLD services, study groups may have differed on a wide variety of unobserved variables. For example, most studies reviewed here examined group equivalence in terms of sociodemographic or mental health variables. No study examined other potentially predictive variables, such as motivation to participate in treatment or past criminal behavior. A further limitation of the studies included in this review was related to the relatively small number of participants in most evaluations and the resulting lack of statistical power.

\section{Service variability}

CJLD services are by their nature nonstandardized, and their efficacy is likely to depend on a range of factors related to both the internal structure of the service (for example, selection of participants, funding, and staff) and external factors, such as care system variables (for example, the availability of effective community services). CJLD services appear to be successful in terms of identifying offenders with mental disorders and linking them to available services. The studies reviewed also examined services in terms of changes in mental health status or recidivism. Arguably, such changes may be more likely to be associated with the availability and efficacy of support services in the community than with the CJLD service itself. The latter may represent a gateway into services but may be successful only if appropriate and effective communitybased services are available.

\section{Implications for research and practice}

The studies included in this review represent the highest quality research evidence available. A key advantage of synthesizing the available literature lies in its ability to clarify the limited extent of our knowledge and provide a basis for planning future highquality research. An important finding to emerge from this review is the marked lack of good research evidence and the wide variety of CJLD service models. This finding partly results from the fact that during the initial development of CJLD services, no national policy framework existed to guide their direction and development $(1,12)$. As a result, services were configured to reflect local needs and according to the availability of services at a given time and place $(1,2)$. Under such circumstances, the ability of services to consistently meet the complex needs of offenders with mental disorders is questionable.

Any service framework should be informed by the rigorous testing of CJLD services in a range of locations $(1,23)$. Further studies should ensure adequate sample sizes and incorporate a common set of outcome measures that will facilitate service evaluation and improvement (31). Available evidence suggests that CJLD services should include robust mental health screening and open referral mechanisms. Furthermore, to respond to the often complex needs of offenders with mental disorders, an effective service probably needs to have a multidisciplinary team with the capacity to access a range of services related to housing, addiction, vocational rehabilitation, and social services, in addition to formal mental health care. Also, further studies are required to examine which type of patients can benefit most from these service models and what mechanisms contribute to positive outcomes (23). Evidence suggests that identifying offenders with mental disorders and simply informing them about available services is an ineffective way to encourage engagement with services. A more effective intervention to promote treatment compliance is likely to involve formal agreement on a structured treatment program by offenders with mental disorders, their relatives or significant others, and service providers. Further research is required to examine how to improve treatment engagement and the effectiveness of sanctions for noncompliance with treatment programs.

\section{Conclusions}

Overall, the evidence presented here suggests that CJLD services can be an effective mechanism to identify offenders with mental disorders within the criminal justice system and successfully link them to health and social services. Evidence also indicates that these services can help to reduce recidivism and improve mental health outcomes. However, findings should be interpreted with caution because of the quality of the evidence, the range of existing CJLD models, and the differences in participant groups. These inadequacies can be addressed only through further high-quality, systematic research, preferably across a number of services and jurisdictions and incorporating a range of standardized measures and outcomes. More important, although evidence appears to support the concept of liaison and diversion, it should be recognized that the development, formation, and implementation of a CJLD service must take place according to system-of-care principles and in recognition of a spectrum of needs and related care responses.

\section{Acknowledgments and disclosures}

This review was funded by project grant MRD 12/77 from the National Institute for Health Research and by an award from the Campbell Collaboration.

The authors report no competing interests.

\section{References}

1. Bradley K: The Bradley Report: Lord Bradley's Review of People With Mental Health Problems or Learning Disabilities in the Criminal Justice System. London, Her Majesty’s Stationery Office, 2009

2. Parsonage M, Khanoum H, Rutherford M et al: Diversion: A Better Way for Criminal Justice and Mental Health. London, Sainsbury Centre for Mental Health, 2009

3. Birmingham L: Diversion from custody. Advances in Psychiatric Treatment 7: 198-207, 2001

4. Petrila J: Diversion from the criminal justice system. Behavioral Sciences and the Law 23:161-162, 2005

5. Fazel S, Danesh J: Serious mental disorder in 23,000 prisoners: a systematic review of 62 surveys. Lancet 359:545-550, 2002

6. Singleton N, Meltzer H, Gatward R Psychiatric Morbidity Among Prisoners in England and Wales. London, Office for National Statistics, 1998

7. Redlich A, Liu S, Steadman H, et al: Is diversion swift? Comparing mental health court and traditional criminal justice processing. Criminal Justice and Behavior 39: 420-433, 2012

8. Goodale G, Callahan L, Steadman HJ: What can we say about mental health courts today? Psychiatric Services 64:298-300, 2013 
9. James DV, Farnham F, Moorey H, et al: Outcome of Psychiatric Admission Through the Courts. London, Home Office, 2002

10. McGilloway S, Donnelly M: Mental illness in the UK criminal justice system: a police liaison scheme for mentally disordered offenders in Belfast. Journal of Mental Health 13:263-275, 2004

11. Provision for Mentally Disordered Offenders. Circular 66/90. London, Home Office, 1990

12. Reed J: Review of Health and Social Services for Mentally Disordered Offenders and Others Requiring Similar Services. London, Her Majesty’s Stationery Office, 1992

13. Steadman HJ, Scott JE, Osher F, et al: Validation of the Brief Jail Mental Health Screen. Psychiatric Services 56:816-822, 2005

14. Belenko S: Research on Drug Courts: A Critical Review: 2001 Update. New York, National Center on Addiction and Substance Abuse at Columbia University, 2001

15. Appraising the Evidence. Oxford, United Kingdom, Critical Appraisal Skills Programme. Available at www.casp-uk.net/ find-appraise-act/appraising-the-evidence

16. Systematic Reviews: CRD's Guidance for Undertaking Reviews in Health Care. York, United Kingdom, University of York, Centre for Reviews and Dissemination, 2009. Available at www.york.ac.uk/inst/crd/ pdf/Systematic_Reviews.pdf
17. Pettigrew M, Roberts H: Systematic Reviews in the Social Sciences: A Practical Guide. Oxford, Blackwell, 2006

18. Cosden M, Ellens JK, Schnell JL, et al: Evaluation of a mental health treatment court with assertive community treatment. Behavioral Sciences and the Law 21 415-427, 2003

19. Cosden M, Ellens J, Schnell J, et al: Efficacy of a mental health treatment court with assertive community treatment. Behavioral Sciences and the Law 23:199-214, 2005

20. Boothroyd RA, Poythress NG, McGaha A et al: The Broward Mental Health Court: process, outcomes, and service utilization. International Journal of Law and Psychiatry $26: 55-71,2003$

21. Boothroyd RA, Mercado CC, Poythress NG, et al: Clinical outcomes of defendants in mental health court. Psychiatric Services 56:829-834, 2005

22. Christy A, Poythress NG, Boothroyd RA et al: Evaluating the efficiency and community safety goals of the Broward County Mental Health Court. Behavioral Sciences and the Law 23:227-243, 2005

23. Steadman HJ, Redlich A, Callahan L, et al: Effect of mental health courts on arrests and jail days: a multisite study. Archives of General Psychiatry 68:167-172, 2011

24. McNiel DE, Binder RL: Effectiveness of a mental health court in reducing criminal recidivism and violence. American Journal of Psychiatry 164:1395-1403, 2007

25. Moore ME, Hiday VA: Mental health court outcomes: a comparison of re-arrest and re-arrest severity between mental health court and traditional court participants. Law and Human Behavior 30:659-674, 2006

26. Broner N, Lattimore PK, Cowell AJ, et al: Effects of diversion on adults with cooccurring mental illness and substance use: outcomes from a national multi-site study. Behavioral Sciences and the Law 22: 519-541, 2004

27. Hoff RA, Baranosky MV, Buchanan J, et al: The effects of a jail diversion program on incarceration: a retrospective cohort study. Journal of the American Academy of Psychiatry and the Law 27:377-386, 1999

28. Wilson S: The principle of equivalence and the future of mental health care in prisons. British Journal of Psychiatry 184:5-7, 2004

29. The Bamford Review of Mental Health and Learning Disability (Northern Ireland) Forensic Services. Belfast, United Kingdom, Department of Health, Social Services and Public Safety, 2007

30. Birmingham L, Wilson S, Adshead G: Prison medicine: ethics and equivalence. British Journal of Psychiatry 188:4-6, 2006

31. Review Into the Current Practice of Court Liaison and Diversion Schemes. London, Centre for Public innovations, 2005

\section{Change of E-Mail Addresses for Authors and Reviewers}

Psychiatric Services authors and reviewers are reminded to visit ScholarOne Manuscripts at mc.manuscriptcentral.com/appi-ps and keep the contact information in their user account up to date. Because the system relies on e-mail communication, it is especially important to keep e-mail addresses current. If you have questions about the information in your user account, contact the editorial office at pscentral@psych.org. 